\title{
Case Report on Diabetic Amyotrophy
}

\author{
Palanisamy Sivanandy ${ }^{\star 1}$, Rasna James ${ }^{2}$ \\ 1'Department of Pharmacy Practice, International Medical University, Kuala Lumpur, MALAYSIA. \\ ${ }^{2}$ Deparment of Clinical Pharmacy, Kovai Medical Center and Hospital, Coimbatore, INDIA.
}

\begin{abstract}
Diabetic amyotrophy is a rare complication associated with early-stage diabetes. The main symptoms are muscle weakness and pain, usually in the hips and thighs, leading to difficulty in standing and walking. It usually occurs in patients over 60 years of age and hence its morbidity is increased. However, diabetic amyotrophy (DA) is one complication which seems always to respond to better glycaemic control and if this can be achieved the prognosis is good. Here we report a case on non-insulin-dependent diabetes mellitus, who developed diabetic amyotrophy.
\end{abstract}

Key words: Diabetes, Insulin, Amyotrophy, Neuropathy, Muscles.

\section{INTRODUCTION}

Diabetic amyotrophy is a disabling illness that is discrete from other forms of diabetic neuropathy and it is also known as proximal diabetic neuropathy, diabetic lumbosacral radiculoplexus neuropathy, and diabetic polyradiculoneuropathy, occurs in patients with diabetes. It is more likely present in those with type II than type I diabetes. ${ }^{1}$ It is characterized by weakness followed by wasting of muscles, either unilaterally or bilaterally, with excruciating pain in the muscles of the thigh, hip, and buttocks. Impairment of sensation in the affected area is minimal in the cutaneous distribution sharing the same root or peripheral nerve as affected musculature. The symptoms are fairly sudden onset and occurs usually on one side of the body, sometime both sides. ${ }^{2}$ Diabetic amyotrophy is most common in middle age groups or later, while it may occur in youth. Approximately $1-2 \%$ of those adults with diabetes will acquire this condition. A concomitant distal predominantly sensory neuropathy may be present. Electro-diagnostic methods are most unswervingstudies with a neurogenic lesion attributable to a lumbosacral radiculopathy, proximal crural neuropathy or plexopathy. ${ }^{3}$ The course of illness iscapricious with gradual improvement but often incomplete, site of the lesion and pathogenesis of Diabetic amyotrophy are remain controversial.

\section{CASE REPORT}

A 66 year old male weighing $80 \mathrm{~kg}$ was presented to the emergency department unit of the hospital. He was complaining of burning sensation on both lower limbs with intermittent itching, bilateral knee pain and with difficulty in sleeping. He showed weak hip flexion, adduction and reduced knee jerk. He was diabetic for the past 15 years and did not take medications regularly. His glycated haemoglobin (HbA1c) value was 7.6\%, the blood glucose was poorly controlled, and fasting blood sugar (FBS) level was fluctuating. His corrected total serum calcium concentration was found to be normal, it was $9.1 \mathrm{mg} / \mathrm{dL}$. He was diagnosed with Diabetic Amyotrophy (DA). The patient was given with steroid, Methyl prednisolone $500 \mathrm{mg}$ intravenously once a day (OD) for 3 days; a combination of Gabapentin (300 mg) and Methylcobalamin (500 $\mathrm{mg}$ ) three times a day (t.i.d) was administered for neuropathic pain. The patient was also administered with his antidiabetic medications, Glibenclamide (5 mg) and Metformine (500 mg) twice daily (b.i.d) for 3 days, along with 10 units of
DOI: 10.5530/ijopp.9.3.13

\section{Address for} correspondence: Dr. Palanisamy Sivanandy,M.Pharm., Ph.D., GCP (MY).,

Lecturer, Department of Pharmacy Practice, School of Pharmacy, International Medical University, JalanJalil Perkasa 19, Bukit Jalil, 57000 Kuala Lumpur WP, MALAYSIA. Mob: +60-1112327819 Email: sivapalanisamy@ yahoo.co.in 
Soluble Insulin as part 30\% twice daily for 4 days. Following corticosteroid therapy, the patient reported a pain relief and was discharged.

\section{DISCUSSION}

Diabetic amyotrophy is mainly caused due to an abnormality of the immune system that damages the small blood vessels which supply the nerves to the legs. This process is also known as microvasculitis. It occurs very rarely in non-diabetes patients. The raised blood sugar level does not directly damage the nerves, but it may upsurge in some way to the process of damage.The incidence is common in type 2 diabetes (1 in 100) patients that type 1 diabetes $\left(3\right.$ in 1,000). ${ }^{4,5}$ It is more common in adults above the age of 50 years, although younger peoples can also be affected. ${ }^{6-8}$

The best possible way to limit the DA is early diagnosis, goodcontrol of blood glucose, together with regular exercise, muscular activity and physiotherapy. ${ }^{9}$ Muscular activities are very essential to minimise wasting of muscles and to improve the speed and degree of recovery. Lifestyle modifications like diet control and quitting smoking proven the control over DA.

Medications are mainly given to control the neuropathic pain, often conventional pain killers like paracentamol are used for the nerve pain. ${ }^{7}$ Sometime amitriptyline, tricyclic antidepressants, antiepileptics drugs and immunosuppressant's are also given to control the pain. ${ }^{8}$

In our case, we found that the patient glycemic control is poor and the patient seems to be obese. The patient was educated about the importance of glucose control and reduction of body weight. The patient neuropathic pain was treated with Gabapenting and Methylcobalamine, along with Methyl predinisolone. Glibenclamide and Metformine, along with 10 units of soluble Insulin as part was given to lower the elevated glucose level. Following corticosteroid therapy, the patient reported a pain relief and was discharged with regular medications. Patient was informed about the recurrence of DA and insisted to adhere with the regular medication and glucose control.

\section{CONCLUSION}

The incidence of diabetes and diabetic amyotrophy are increasing every year with remarkable number of modalities. Hence, early diagnosis are warranted to prevent the complication of diabetes and to prevent the undue delay in the management of the condition. Regular monitoring of blood glucose is necessary while investigating any form of neuropathic complications.

\section{ACKNOWLEDGEMENTS}

We are thankful to Management, KMCR \& ET and Principal of KMCH College of Pharmacy for providing necessary facilities and support.

\section{CONFLICT OF INTEREST}

The authors have no conflicts of interest.

\section{REFERENCES}

1. Sander HW, Chokroverty S. Diabetic amyotrophy: current concepts. Seminars in Neurology. 1996;16(2):173-8. http://dx.doi.org/10.1055/s-2008-1040973; PMid:8987131.

2. Diabetic Amyotrophy. Patient. [Online] Available from: patient.info/health/ diabetic-amyotrophy-leaflet Accessed on August 8, 2016.

3. Subramaniam N, Chandrashekaraiah S, Christopher MJ. Diagnosis and management of diabetic amyotrophy. Endocrinology. 2010:327-329. Available from: https://www.gmjournal.co.uk/uploadedFiles/Redbox/Pavilion_ Content/Our_Content/Social_Care_and_Health/GM_Archive/2010/June/ June2010p327.pdf.

4. Younger DS, Rosoklija G, Hays AP, Trojaborg W, Latov N. Diabetic peripheral neuropathy: a clinicopathologic and immunohistochemical analysis of surval nerve biopsies. Muscle Nerve. 1996;19(6):722-7. PMID: 8609922 http://dx.doi. org/10.1002/(SICI)1097-4598(199606)19:6<722::AID-MUS6>3.0.CO;2-C: http://dx.doi.org/10.1002/(SICI)1097-4598(199606)19:6<722::AIDMUS6>3.3.CO;2-D.

5. Kawagashirea $\mathrm{Y}$, Watanabe $\mathrm{H}$, Oki $\mathrm{Y}$, lijima M, Koike $\mathrm{H}$, et al. Intravenous immunoglobulin therapy markedly ameliorates muscle weakness and severe pain in proximal diabetic neuropathy. Journal of Neurology Neurosurgery and Psychiatry. 2007;78(8):899-901. http://dx.doi.org/10.1136/jnnp.2006.111302; PMid:17635982 PMCid:PMC2117752.

6. Tamburin S, Magrinelli F, Favaro F, Briani C, Zanette G. Long-term response of neuropathic pain to intravenous immunoglobulin in relapsing diabetic lumbosacral radiculoplexus neuropathy. A case report. Pain Practice. 2014;14(2):E85-90. http://dx.doi.org/10.1111/papr.12133 ; PMid:24152254.

7. Chan YC, Lo YL, Chan ES. Immunotherapy for diabetic amyotrophy. Cochrane Database Syst Rev. 2012;3:CD006521. PMID: 22696358 http://dx.doi. org/10.1002/14651858.cd006521.pub3.

8. Gareth JL. The diabetic neuropathies: types, diagnosis and management. Journal of Neurology Neurosurgery and Psychiatry. 2003;74:ii15-ii19.

9. Aaberg ML, Burch DM, Hud ZR, Zacharias MP. Gender differences in the onset of diabetic neuropathy. Journal of Diabetes and its Complications. 2008;22(2):83-7. http://dx.doi.org/10.1016/j.jdiacomp.2007.06.009 ; PMid:18280437. 